\title{
Hemp is the Future of Plastics
}

\author{
Ali Asghar Modi ${ }^{1}$, Rehmatullah Shahid ${ }^{1}$, Muhammad Usman Saeed ${ }^{1}$, Tanzila Younas ${ }^{2 *}$ \\ ${ }^{1}$ Student, Szabist, Karachi and 75600, Pakistan \\ ${ }^{2}$ Assistant Professor, Szabist, Karachi and 75600, Pakistan
}

\begin{abstract}
Plastic is the world's most adaptable material. From bikes to food wraps and from jets to pencils, you can make anything and everything from plastics. With the infinite number of uses, plastic also have some devastating impacts on our planet. Most plastics produced today are made using petroleum-based compounds that release harmful gases into the atmosphere. Waste solutions are inefficient, and harmful by-products toxic our land, water and wildlife. Yet, consider the possibility that there was a way to deal with deliver the greater part of what we utilize causes a negative greenhouse impact, is sustainable and biodegradable and has just about an indistinguishable cost to our present techniques. Meet Hemp plastic, an only plastic that's $100 \%$ biodegradable in nature if produce by using only Hemp plant. Hemp plant consumes 4 times more carbon dioxide then other plants from atmosphere. The fiber we can produce from hemp is stronger than the conventional fiber we are using these days. This paper is intended to show numerous benefits of using hemp for the manufacturing of biodegradable plastic (HEMP PLASTIC) rather than conventional plastics.
\end{abstract}

\section{Introduction}

Today plastic is one of the most used materials in the world but its voyage through time was not easy. Plastics are simply the carbon chained polymers and the shape of these polymers' gives plastics their plasticity, allowing them to be molded into any shape which is why they are the world's most adaptable material. The word plastic is a typical term that is utilized for some materials of a manufactured or semi-engineered nature. The term was gotten from the Greek plastikos, which signifies "fit for enlargement."[1] Another reason of the vast use of plastics is its manufacturing cost which is quite cheap when compared to the manufacturing of same stuff with different materials.

Since each photo has two sights, similarly plastics have some devastating effects on Earth, directly as well as indirectly. Majority of the plastics is being produced by using petroleum based compounds which releases harmful gases during synthesizing, contaminating the Earth's atmosphere.

Not only the manufacturing of plastics, but also its endurance towards the degradation is also a major drawback. Every piece of plastic that was ever produced and was not recycled still exists except biodegradable plastics, which are degradable to some extent. [2]

Therefore, to reduce the increasing environmental pollution from synthetic plastic an alternative must be developed. This need can be fulfilled by use of hemp plastic, which is $100 \%$ biodegradable if produced using only Hemp plant.

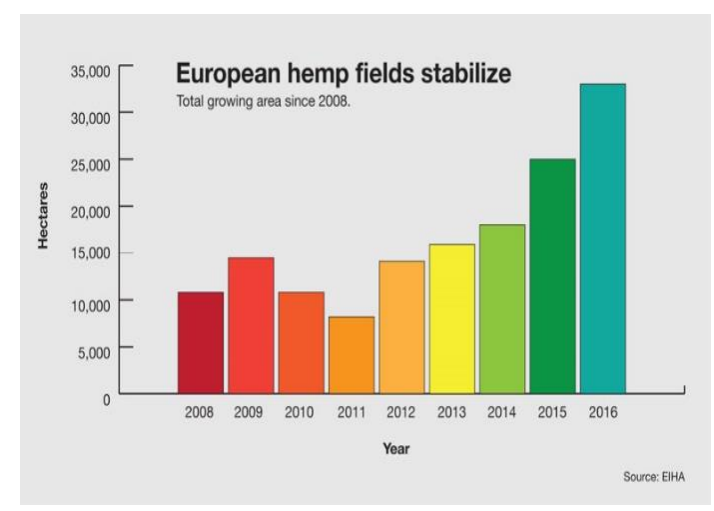

Figure 1. Increase in the fields of Hemp plant [3].

\section{Types of Plastics}

In order to understand the different types of plastics, one needs to understand its composition and categorizing criteria. Plastic is any synthetic or semi-synthetic organic polymer. While plastics might be produced using pretty much any natural polymer, most mechanical plastic is produced using petrochemicals. The expression "plastic" refers to the property of flexibility, which is the capacity to disfigure without breaking. The polymer used to make a plastic is quite often blended with added substances, including colorants, plasticizers, stabilizers, fillers, and fortifications. These added substances influence the concoction structure, synthetic properties, and mechanical properties of a plastic and furthermore influence its cost. The composition and the manufacturing of plastic categorize plastics mainly in Biodegradable plastics and Non-biodegradable plastics.

*Corresponding author: tanzila@szabist.eu.pk 
As the name suggest, biodegradable plastics are produced using petro-chemicals just like conventional plastics except some additives are included in their manufacturing which helps them in there fast degradation. Biodegradable plastics don't always break down into harmless substances, sometimes they leave behind a toxic residue and that makes them generally (but not always) unsuitable for composting. They can be breakdown using microorganisms into water, carbon dioxide and some bio chemical. And when they are put into the landfills they produce harmful greenhouse gases when breaking down, which makes them more toxic then other conventional plastics. Some examples of biodegradable plastics are polybutyrate (PBAT), polycaprolactone (PCL), polylactic acid (PLA) and polyhydroxalkanoate (PHA).

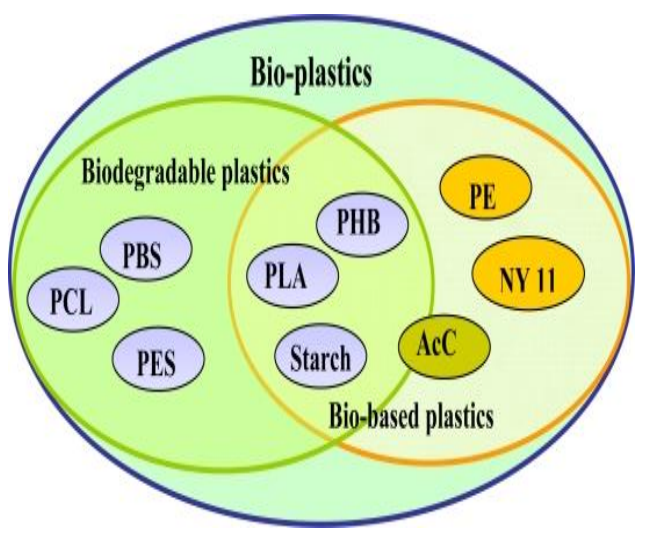

Figure 2. Examples of biodegradable plastics and bio-plastics[4].

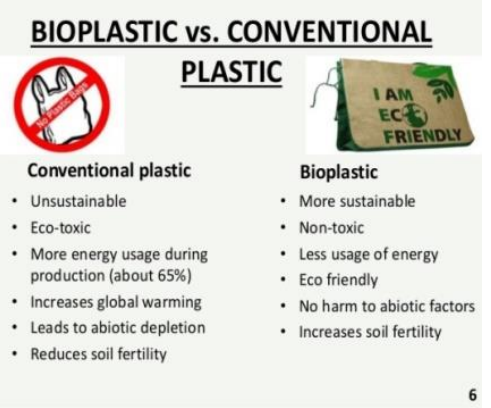

Figure 3. Basic comparison of bio-plastic and conventional plastic [6].

Conventional plastics or non-biodegradable plastics are mostly chemically inert i.e. resistant to degradation, consequently ends up disrupting the wildlife, oceans and land. [5] And one of the most destructive impact of conventional plastic is that it is produced by the nonrenewable source i.e. Petroleum.

These impacts are fueling the international drives for the production of biodegradable polymers.

\section{Uses of Plastics}

The flexibility of plastic materials originates from the capacity to mold, laminate or shape them, and to modify them physically and synthetically. Once anything made of plastic was considered to be of low quality but now that is history. Now days from the zip of your pants to the bikes you are riding are made up of plastics. Even the food industry uses an enormous amount of plastic. Yoghurt and butter comes in plastic tubs, Cheese in plastic wrap, water and milk in plastic containers. It is even use in construction industry in great amount. They have great versatility and combine excellent strength to weight ratio, durability, cost effectiveness, low maintenance and corrosion resistance, which make plastics an economically attractive choice throughout the construction sector. Its versatility is the reason that a Plastic is suitable for any situation. The following paragraphs will brief about the usage of plastic across the globe.

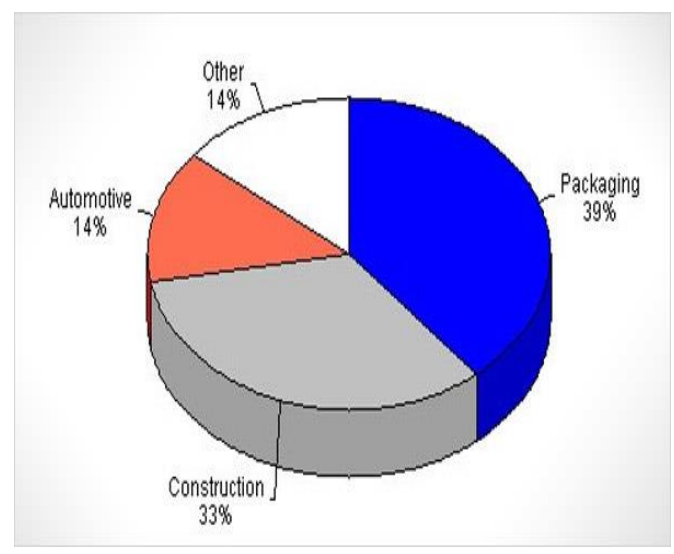

Figure 4.Uses of Plastic in different type of industries [7]

\subsection{In Food Packaging}

From airtight wraps to shelf stable bottles and vessels, plastic packaging plays a key role in keeping the food safe while supplying it from farm to the consumer and is a best used material for freezing foods for longer term storage. [8] Plastics are versatile, hygienic, lightweight, flexible and highly durable. Due to such qualities, plastic is used in numerous packaging applications.

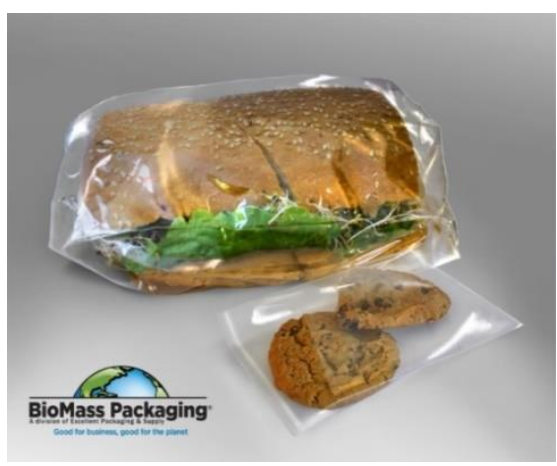

Figure 5. Use of plastic in food packaging.

\subsection{In Construction}

Plastics are used in a growing range of applications in the construction industry. It's durability is one of the reason why it is used so frequently in construction as being corrosion resistant, allowing it to survive in any 
weather.[9] These days, cost is an important factor in industries and Plastics are one of the most economical material. And an amazing property of plastic i.e. recycling beat metals in most of the places in industries.

\subsection{In Transport}

The financially savvy and safe transportation of individuals and merchandise is essential to our economy, cutting the weight of cars, airplanes, boats and trains can cut fuel consumption dramatically. The lightness of plastics therefore makes them priceless to the transport industry. Plastics are even used in combination with other materials are used as structural elements in all kinds of transport, even skateboards, roller blades and bicycles. [10]

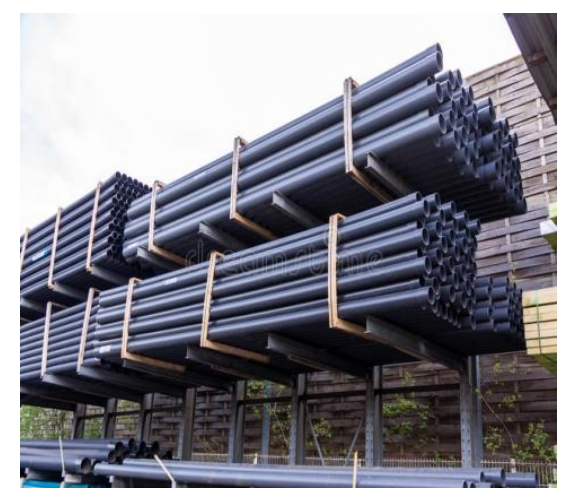

Figure 6. Use of plastic in construction.

\section{Comparison of Hemp with Conventional plastics}

The main factors which requires the replacement of conventional plastics by Hemp plastic includes its toxicity, chemically inertness, manufacturing hazards and the limited amount of natural resources. The following paragraphs enlighten some details on the comparison of conventional and hemp plastics and the need to replace them.

\subsection{Composition}

The ENE compounds, Toluene, benzene, things like that, which are the most poisonous derivatives of plastics that are produced from hydrocarbons aren't found in Hemp. [11]

\subsection{Manufacturing}

Most of the conventional plastic today is manufactured using petroleum based compounds and petroleum consumption is considered harmful to the environment, given the measure of waste created amid the refinement procedure and the destructive techniques used to separate oil from the earth. And simultaneously we are losing one of most important natural resource i.e. Petroleum in the manufacturing of plastics. On the other hand, hemp plastic is solely produced using the cellulose extracted from hemp plant and therefore causes no toxicity during its production.

\subsection{Biodegradable and Recyclable}

Hemp plastic is $100 \%$ biodegradable and recyclable when it is made using completely a Hemp plant. We traditionally think of recycling as the conversion of waste into usable material, although if we use more hemp plastic, we could introduce a new cycle that would be much more environmentally friendly. Plants are harvested and broken down into vital components for production and a product is produced. After its utilization, it is put into a landfill where nature will run its course and separate it into required supplements basic for the plant's development and the cycle is finished. [12]

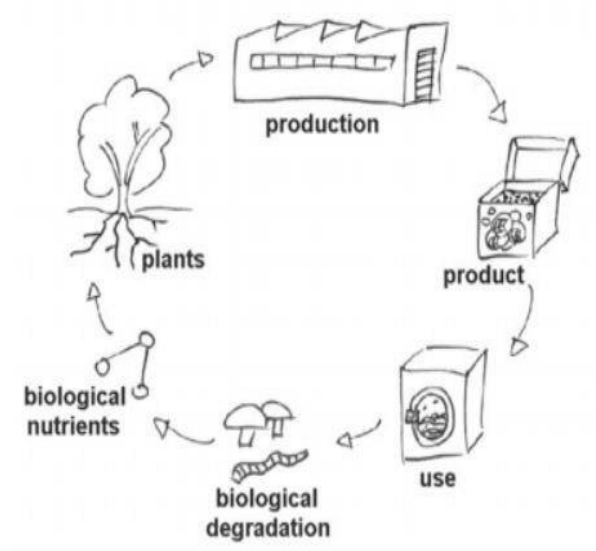

Figure 7. Cycle of hemp plastic.

\subsection{Environment friendly}

Hemp absorbs four times the amount of carbon dioxide as trees do amid its snappy 12-14 week develop cycle. Delivering hemp plastic likewise requires $22-45 \%$ less energy than non-renewable energy source based items [13]. We can have fields, acres and acres, hectares of hemp farms that are pulling carbon dioxide out of the atmosphere (as plants do). Then, that carbon from the carbon dioxide in the atmosphere gets used to make the plastics, and the plastics, when they are going into a landfill and they are no longer usable, will biodegrade bringing carbon back into the soil. So, it's essentially carbon negative, pulling carbon out of the atmosphere and putting it back into the soil.

\subsection{Applications}

The strength of hemp plastic makes it appealing in several industries. The automotive, building, and packaging industries are all being turned on to hemp plastic. It is also lightweight and has a very high ratio of density to weight. This allows it to potentially be used in aerospace to save weight on heavy structures. Due its versatility, hemp can be used anywhere for any purpose replacing conventional plastics.

\subsection{Production cost}

Plastics produced using petroleum compounds are quite cheap and easy to manufacture and on the other hand, the processes involve in the production of biodegradable plastic or specifically hemp plastics are quite expensive and use more effort than the production of conventional plastics. 


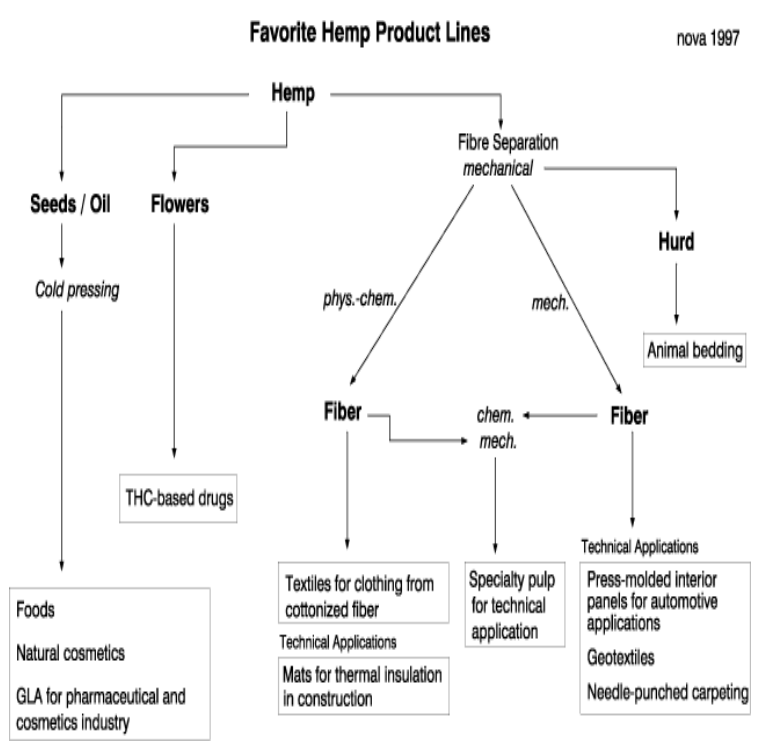

Figure 8. Applications of Hemp plant [14].

\section{Energy Required to Process}

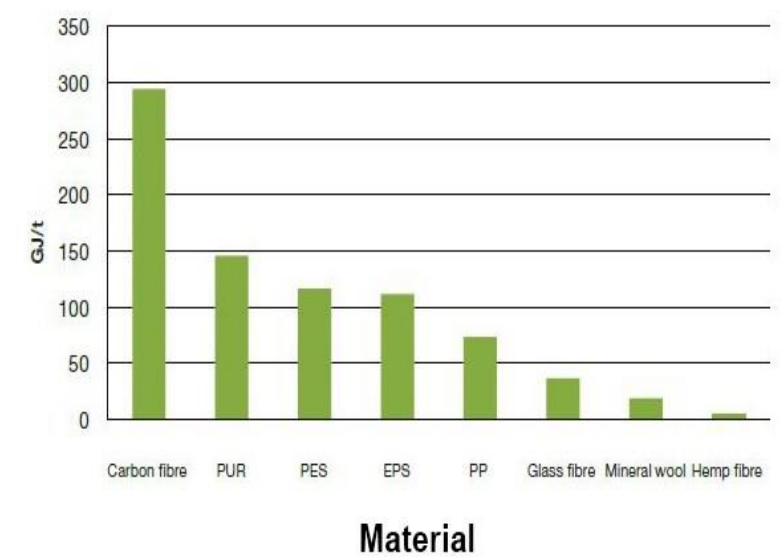

Figure 9. Energy required for the production of different type of plastics.

\subsection{Toughness and Flexibility}

Hemp Plastics can be five times stiffer and 2.5 times stronger than polypropylene, and it will not cause wear and tear to the screw and the mold like glass fibers do, and unlike glass fibers, it does not pose safety and health risks. [14] Its flexibility is one of the greatest factors for its superiority over conventional plastics.

\section{Conclusion}

With an ever increasing number of plastics being utilized in human lives and expanding weight being set on limits accessible for plastic wastes disposal, the need for biodegradable plastics and biodegradation of plastic wastes have gained increasing importance in the last few years. Also the available sources of petroleum oil is declining (which is the major source of conventional plastics) adds up for the need of an alternative way of creating plastics. In any case, countries all through the world do understand that petrochemical utilization should be lessened, and hemp is being perceived as a reasonable contrasting option to these plastics. There are number of different bio plastics are available but the best one among them is Hemp. Many factors as discussed above prove hemp to be better than other bio plastics such as its lightweight, versatility, degradation time etc. Though producing plastics using only hemp plants causes more efforts and money but the impacts that conventional and other bio plastics are causing to this Earth are getting unbearable and therefore conventional plastics should be completely replaced with hemp plastics.

\section{References}

1. Precision Engineered Products [Online]. Available: http://www.pepctplastics.com/resources/connecticut -plastics-learning-center/an-introduction-to-plastics/

2. L.Concialdi, May 03,2016. [Online]. Available: https://discovercbd.com/blogs/cbdnews/105784134-benefits-of-hemp- plastic-overtraditional-plastic

3. Hemp Today. March 27,2017. [Online]. Available: https://hemptoday.net/european-hemp-fields-grow/

4. L.Y. Beeker, M. Pringle Joshua, M. Pearce. International Journal of Molecular Sciences (September, 2009)

5. A.M.Helmenstine, November 15, 2016. [Online]. Available: https://www.thoughtco.com/plasticchemical-composition-608930

6. October, 2012. [Online]. Available: https://www.slideshare.net/ShwetaChand2/bioplastic $-66639489$

7. Presto Testing Instruments. [Online]. Available: http://www.testing-instruments.com/blog/problemsfaced-by-the-manufacturers-in-plastic-industry-andtheir-solutions/

8. America's Plastic Makers. [Online]. Available: https://www.plasticpackagingfacts.org/plasticpackaging/plastic-packaging-by-industry/foodbeverage/

9. British Plastic Federation. 2018 [Online] Available: http://www.bpf.co.uk/plastipedia/applications/defaul t.aspx

10. T. Johnson. April 01, 2017. [Online] Available: https://www.thoughtco.com/uses-of-plastics-820359

11. J.Hasse, May 05, 2017. [Online]. Available: https://www.benzinga.com/markets/emergingmarkets/17/05/9405826/why-hemp-could-be-thefuture-of-plastics

12. National Hemp Association (NHA), May 17, 2016. [Online]. Available: http://nationalhempassociation.org/hemp-plastic/

13. C. Woodford, June 11, 2017 [Online]. Available: http://www.explainthatstuff.com/bioplastics.html

14. M. Karus and G. Leson. International Hemp Association. Vol. 4 (June 01, 1997) 